\title{
The Prevalence of Excessive Daytime Sleepiness and its Determinants among Workers in Call Center in Fes City
}

\section{Mohammed Elbiaze*}

Professor, Director of Sleep Medicine University Center, Hassan 2 University Hospital, Faculty of Medicine and Pharmacy of Fes, Mohammed Ben Abdellah University, Fes, Morocco

*Corresponding Author: Mohammed Elbiaze, Professor, Director of Sleep Medicine University Center, Hassan 2 University Hospital, Faculty of Medicine and Pharmacy of Fes, Mohammed Ben Abdellah University, Fes, Morocco.
Received: February 29, 2020

Published: April 01, 2020

(c) All rights are reserved by Mohammed

Elbiaze.

\begin{abstract}
The extent of excessive daytime sleepiness (EDS) remains unknown in Morocco. The objectives of this study are to assess the prevalence of EDS, its determinants and performance impacts among workers at a call center in Fes.

This is a descriptive and analytical cross-sectional study of 322 workers of average age of 27.9 years and including a self-quiz on sleep disorders and working conditions with Epworth sleepiness scale (ESS) (Moroccan Arabic version), Pichot's fatigue scale, hospital anxiety depression (HAD) scale and Berlin scale. The total participation rate is 71.5\%. The prevalence of EDS on the Epworth scale is $19.3 \%$. Bivariate analysis shows that the prevalence of EDS is higher (between $24.9 \%$ and $56.2 \%$ ) in case of: start of work before 8am AM, difficulty staying alert, fatigue at work, monotonous noise, degraded working conditions, poor performance, degraded family life, high anxiety score, high depression score, or pichot score $\geq 22$. A significantly higher EDS is found in snorers $39.4 \%$ and those with a positive Berlin score $42.9 \%$.
\end{abstract}

The multivariate analysis shows that the main positive determinants of EDS are: difficulty in staying alert (OR $=3.63)$, fatigue at work $(\mathrm{OR}=8.15)$, monotonous noise $(\mathrm{OR}=2.20)$, snoring $(\mathrm{OR}=2.87)$ and HAD score $>13(\mathrm{OR}=1.65)$. The negative determinants of the EDS are: the beginning working after 8 am $(O R=0.74)$, the performance higher than expected $(\mathrm{OR}=0.30)$ and the work satisfactory performance $(\mathrm{OR}=0.37)$.

Our study highlights the very high prevalence of EDS among call center workers, with working conditions as the main determinant. We have made recommendations based on comprehensive measures to improve working conditions and customized measures for sleepy workers.

Keywords: Shift Work; Excessive Daytime Sleepiness; Epworth Sleepiness Scale; Pichot's Fatigue Scale; Berlin Scale

\section{Abbreviations}

EDS: Excessive Daytime Sleepiness; ESS: Excessive Sleepiness Scale; BMI: Body Mass Index; HAD: Hospital Anxiety Depression Scale; OSA: Obstructive Sleep Apnea

\section{Introduction}

Excessive daytime sleepiness (EDS) is a symptom that occurs with a high prevalence in the general population ranging from 3,9 to $32 \%[1,2]$. Some epidemiological studies have reported an association with work conditions [3].

Work-related EDS is a neglected symptom of both patients and physicians, but it can cause considerable discomfort in socio-professional activities and its causes are numerous.

EDS is implicated in many transport and work accidents. The relationship between sleep, sleepiness, and work is close. It can be linked to sleep deprivation behaviors, sleep-fragmenting diseases, or conditions that produce hypersomnia [4].

Disturbances in alertness and sleep may impair the psychomotor performance of shift workers, particularly those working in call centers.

EDS can be evaluated subjectively at the interview with the analog visual scale, or by the Epworth Sleepiness scale (ESS) based on self-assessment of the frequency of falling asleep in everyday situations [5].

To study the relationship between shift work and the occurrence of EDS, this transversal study was conducted on the population of 322 workers at the WEB HELP call center in Fez. Our study is part of a series of epidemiological studies conducted by the Sleep Medicine University Center (SMUC) of Fez concerning sleep disor- 
ders. Our main objective is to assess the prevalence of EDS, its determinants and impact on performance among workers in this call center. Our secondary objectives are to assess sleep quality and the prevalence of other sleep disorders that can cause EDS.

\section{Materials and Methods}

Study design and sample selection

Of the 1977 workers at the Web Help Call Centre in Fez at its 3 sites, 322 were surveyed. Our survey uses a randomized sampling, without any criteria of inclusion or exclusion by using convenience sampling and standardized sample formula

$N=k \times \pi \times(1-\pi) \times\left(z_{\alpha} / p\right)^{2}$.

This is a descriptive and analytical cross-sectional study of 322 workers of average age of 27.9 years and including a self-quiz on sleep disorders and working conditions. It included also 4 scales: ESS (Arabic version) Pichot Fatigue scale, Hospital Anxiety Depression scale (HAD) and Berlin test. The total participation rate of $71.5 \%$. Anonymity was respected throughout the investigation. The questionnaire includes:

1. Sleep assessment questionnaire used at our Sleep Center in French and Arabic, which includes 5 topics: Lifestyle, global sleep quality assessment, sleep hygiene, snoring and apnea, sleep behavior disorders.

2. Working conditions: Inspired by the COPREV questionnaire (Association of Belgian Occupational Health and Safety Services) which assesses night and shift work and working conditions (French version) [6]. It includes these topics: health problems linked to work and working conditions.

3. Evolution of socio-professional life at work: This is an extract of the French Health Barometer 2010 questionnaire $[7,8]$. It assesses the performance and productivity at work and the evolution of emotional and family life and the evolution of working conditions since recruitment to the call center.

4. ESS [4]: It is a questionnaire to measure a person's risk of daytime sleepiness in daily life. It includes 8 items of everyday situations and 4 degrees of responses from 0 to 3 , with a maximum score of 24. A score of 10 or higher indicates EDS. We used the Arabic version translated by our center according to the rules of transcultural translation.

5. The Hospital anxiety depression scale (HAD) [9]: The HAD is an instrument for detecting anxiety and depressive disorders. It has 14 items rated from 0 to 3 . Seven questions relate to anxiety (total A) and seven others to the depressive dimension (total D). The maximum score is 21. Depression is questionable for a score between 8 and 13, and certain for a score of 13 .

6. Pichot's fatigue scale [10]: Tiredness is a feeling of physical and mental weakening that usually occurs after a sustained effort and that consequently requires a period of rest. Pathological tiredness is referred to when people find it harder to carry out their daily activities than in their usual condition. Pichot's subjective scale has been proposed to assess the importance of this handicap using. Of eight proposals, the subject determines which ones best correspond to its state by assigning each item a score between 0 and 4 . A total of more than 22 is in favor of excessive fatigue for a maximum score of 32 .

7. The Berlin Scale [11]: It is a self-quiz to assess the probability of having obstructive sleep syndrome (OSA) It consists of:

- Category 1: Includes six questions, one question on anthropological measures (age, sex, weight, height) and 5 questions on snoring and apnea. Category 1 is positive with at least 2 positives responses to questions 2 to 6 .

- Category 2: Is interested in daytime sleepiness. Category 2 is positive with at least 2 positives responses to questions 7 to 9 .

- Category 3: Concerns high blood pressure and BMI. Category 3 is positive with at least 1 positive response and/ or a $\mathrm{BMI}>30$.

At least 2 positive categories indicate a high probability of OSA.

\section{Statistical analysis}

All data collected was coded and entered on Excel (Microsoft office 2007). The data analysis was carried out by IBM SPSS software (version 20.0 Chicago IL, USA). The results were presented in the form of percentage and average-standard deviation. Comparisons of prevalence of sleepiness, were made between different groups of risk factors using bivariate analysis with conventional statistical tests (Chi2). The descending step-by-step logistic regression model was used to find the determinants of sleepiness in the study population by adjusting for the various confounding factors.

All variables, including p-value of 0.25 in the bi-varied analysis, were included in the original model. Only the variables for which $\mathrm{p}<0.05$ What included in the final model. The results were presented in the form of Odds Ratio and 95\% confidence interval. All tests of significance were performed at the $5 \%$ level of significance.

\section{Results}

Characteristics of the population

The average age of the study population is $27.9+/-5.46$ (19 to 53 years). Women account for $52.8 \%$ and men $47.2 \%$. It is noted that the representation of both sexes is relatively close. Among the workers, $46,8 \%$ have a body mass index (BMI) of less than 26 while $48,3 \%$ have a BMI between 25 and 30 and $4.6 \%$ have a BMI greater than 30 (Table 1 and 2).

\begin{tabular}{|c|c|c|}
\hline Age & Number & $\mathbf{\%}$ \\
\hline$\leq 30$ years & 238 & 73.9 \\
\hline$>30$ years & 84 & 26.1 \\
\hline
\end{tabular}

Table 1: Distribution by age group.

\begin{tabular}{|c|c|c|}
\hline BM $\mathbf{~}$ & Number & $\mathbf{\%}$ \\
\hline $16-20$ & 12 & 4 \\
\hline $21-25$ & 139 & 46.4 \\
\hline $26-30$ & 145 & 48.3 \\
\hline$>30$ & 4 & 1.3 \\
\hline
\end{tabular}

Table 2: Distribution of workers' $B M I$. 


\section{Health and lifestyle}

Our study showed that $42.9 \%$ of workers have gastrointestinal problems (Graph 1), 17\% have cardiovascular problems (Graph 2) and $1.6 \%$ had a head injury in the past. No case of epilepsy has been reported. Of the 322 surveyed, $1.9 \%$ are known to be diabetic and $1.9 \%$ are followed for hypothyroidism. 39.8\% feel sometimes anxious, sad or depressed. $18 \%$ are chronic smokers with an average of 11.8 cigarettes per day and an average smoking time of 8.5 years. It is also noted that $1.5 \%$ of the workers report smoking cessation and they smoked an average of 15 cigarettes per day, after smoking an average smoking time of 10.4 years.

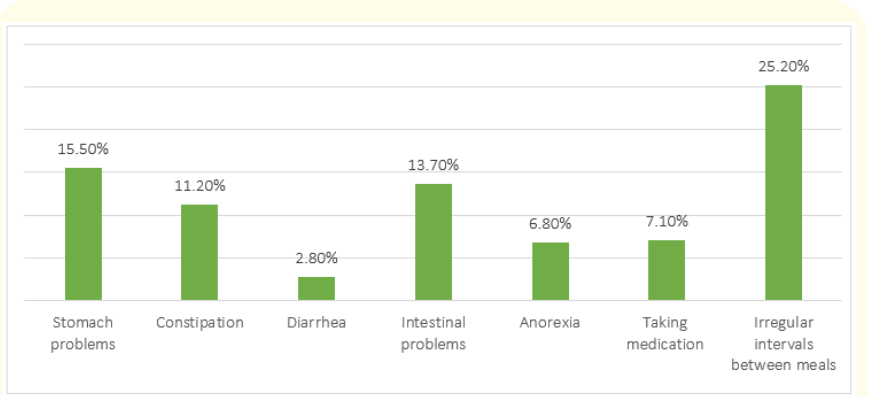

Graph 1: Distribution of recent gastrointestinal problems.

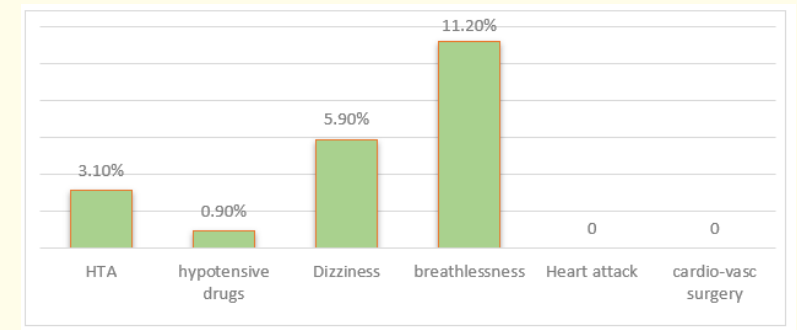

Graph 2: Distribution of cardiovascular problems.

Regarding the consumption of stimulants, $12.4 \%$ take stimulants in the evening. Tea consumption comes first with $85.7 \%$ then coffee with $69,3 \%$ and finally Cola beverage consumption $32.9 \%$. Only $1.9 \%$ reported that they consume alcohol.

\section{Sleep quality assessment}

In graph 3, in the last 3 months, 35.7\% complain of insomnia falling asleep, $33.2 \%$ of frequent nocturnal awakenings, and $25.8 \%$ of waking up too early. Our study also showed that $41.9 \%$ of workers rated their sleep as poor quality. $3.7 \%$ of workers take sleeping pills.

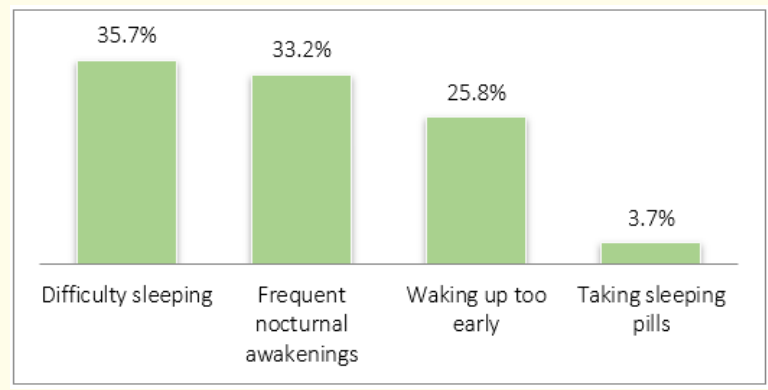

Graph 3: Distribution of sleep quality disorders reported by workers over the past 3 months.
In graph 4 , sleep quality over the past three months is rated good by $39.8 \%$ of subjects, poor by $27.7 \%$ and intermediate by $32.3 \%$.

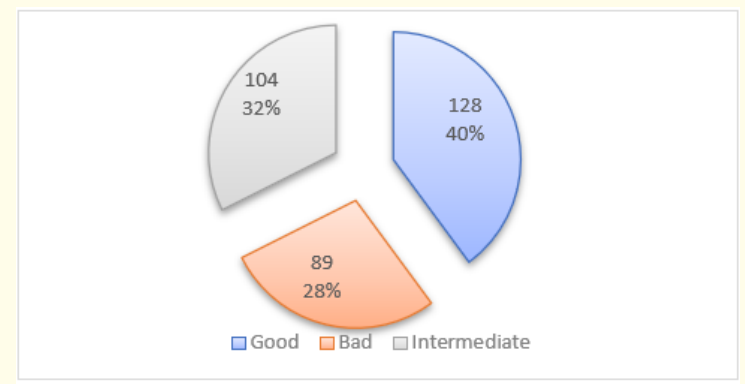

Graph 4: Evaluation of sleep quality during the last 3 months by workers.

The estimated average sleep duration (Graph 5) per night over the past 3 months is less than 6 hours indicating a tendency to sleep deprivation in $7.8 \%$ of workers. $27 \%$ have a sleep duration between 6 and 7 hours and $65 \%$ have at least 7 hours of sleep.

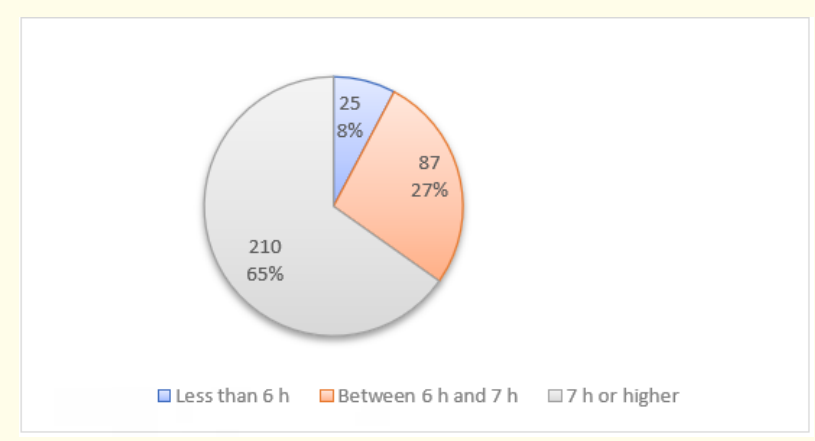

Graph 5: Distribution of estimated sleep duration per night over the last 3 months.

It is noted that the sleep latency (Graph 6) is less than 30 minutes in $56 \%$ of workers, 30 to 60 minutes in $31 \%$, and at least 60 minutes and therefore significantly extended in $13 \%$ of them. The average of sleep latency of workers is 26 minutes (5 to 120 minutes).

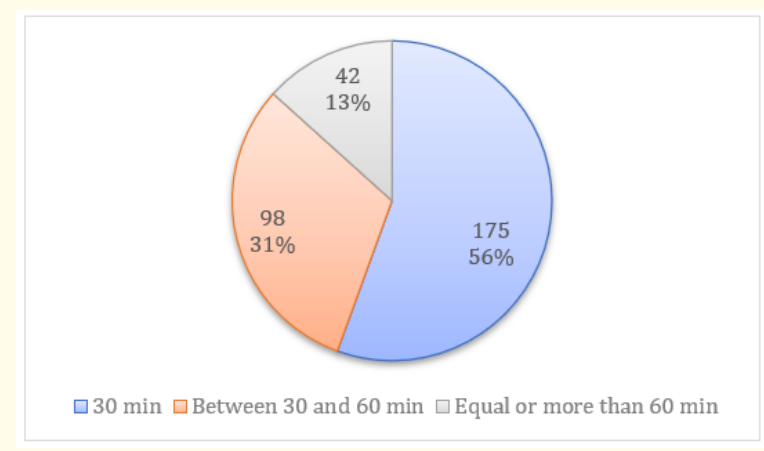

Graph 6: Distribution of sleep latency per night.

\section{Other sleep disorders}

In the last 3 months, snoring has been present in $10.2 \%$ of workers. The average period of evolution of snoring is 4 years $(1-10$ 
years). Respiratory breaks, which are the most important component of sleep apnea, are present in $5.9 \%$ of subjects. Restless leg syndrome is reported by $3.7 \%$ of workers. Other sleep disorders reported in the last 3 months are sleepwalking (3.1\%), somniloquy (15.5\%), bruxism (13.7\%) and finally probable cataplexy (2\%).

\section{Working conditions}

All workers work shifts at interrupted schedules, of which 63.8\% have a variable schedule (modified each week) and 36.2\% have a fixed schedule. $27.9 \%$ start their work at 7 am and the rest start after 8 am.

The average working time per week for workers is between 35 and 48 hours per week for $98.4 \%$ and more than 48 hours per week for $1.6 \%$.

In graph 7, among the working conditions likely to affect the vigilance of call center workers are: repeating same acts, need for sustained attention, fatigue at work, lack of lighting and monotonous noise.

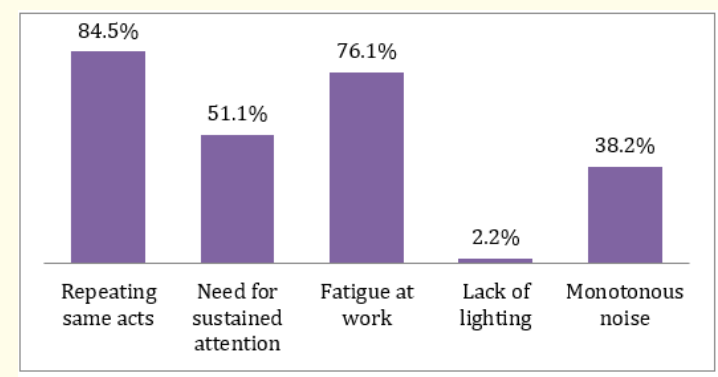

Graph 7: Distribution of working conditions that may impair alertness.

\section{Job performance (Graph 8)}

Work performance is rated excellent (with excellent creativity) by $15.5 \%$ of workers, up to expectations (and average creativity) in $25.8 \%$ of subjects. It is satisfactory and in line with expectations with minimal creativity for $34.2 \%$ of workers and in line with expectations, but a necessary improvement is needed and no creativity for $21.7 \%$. 5\% consider the performance unsatisfactory or unacceptable.

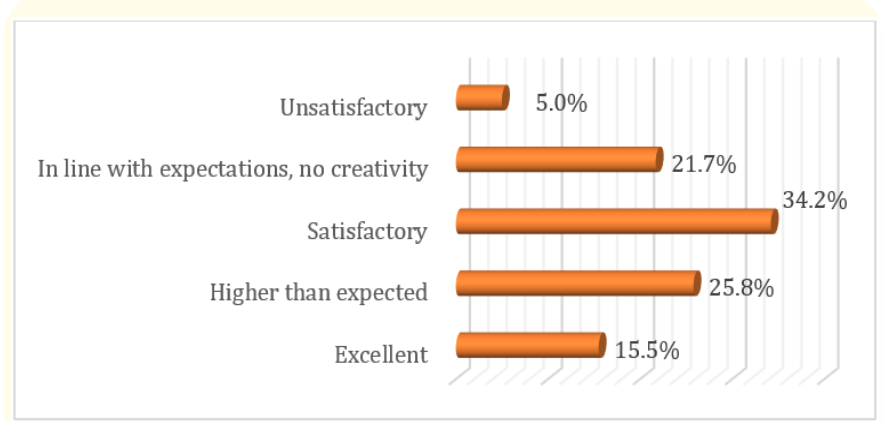

Graph 8: Distribution of levels of Job performance.
Cognitive-behavioral and family impact

In the last three months, $33.5 \%$ reported a change in mood, $24.8 \%$ reported a sharp decline in their memory, and $9.7 \%$ reported a decrease in interest in sex life. 30.7\% report a deterioration in their emotional and family life, while only $16.5 \%$ report an improvement in their family situation. $52 \%$ do not report a change in their personal life. $14.6 \%$ think that their work causes them problems at the family level and $9.3 \%$ think that their work causes them problems as a couple.

\section{Scales analysis (Table 3)}

For ESS, a score of 10 or more defining excessive daytime sleepiness is present in $19.3 \%$ of workers. $1.5 \%$ have severe sleepiness with a score of 16 .

Pichot's score was positive ( $>22$ ) indicating excessive fatigue in $8.1 \%$. For the HAD scale, $34 \%$ have a questionable depression with a score between 8 and 13. 26.7\% suffer from a certain depressive state with HAD score $>13$ and $38.5 \%$ have no signs of depression. Among those with depression, there was a major depressive state (score of 19) in 9\% of workers. For the Berlin scale, $4.3 \%$ have a high probability of obstructive sleep apnea (OSA) with at least two positive categories.

\begin{tabular}{|c|c|c|}
\hline & $\mathbf{N}$ & $\mathbf{\%}$ \\
\hline Epworth $\geq 10$ & 62 & 19,3 \\
\hline Pichot $\geq 22$ & 26 & 8,1 \\
\hline HAD $>13$ & 86 & 26.7 \\
\hline Berlin (2 positive criteria) & 14 & 4,3 \\
\hline
\end{tabular}

Table 3: Distribution of positive scores in Epworth, Pichot, HAD and Berlin scales.

Analysis of excessive daytime sleepiness

The analysis of anthropological data does not objectively differ significantly from EDS.

\begin{tabular}{|c|c|c|}
\hline & ESS $\geq \mathbf{1 0}$ & p \\
\cline { 1 - 2 } Age $\leq 30$ & $17,6 \%(42)$ & \multirow{2}{*}{0,21} \\
\cline { 1 - 2 } Age $>30$ & $23,8 \%(20)$ & \\
\cline { 1 - 2 } Women & $19,4 \%(33)$ & \multirow{2}{*}{0,94} \\
\cline { 1 - 2 } Men & $19,1 \%(29)$ & \\
\cline { 1 - 2 } BMI $<25$ & $17,3 \%(33)$ & \multirow{2}{*}{0,27} \\
\cline { 1 - 2 } BMI $\geq 25$ & $22,1 \%(29)$ & \\
\hline
\end{tabular}

Table 4: Comparison of EDS prevalences by age, gender and BMI of workers.

In table 5, subjects with digestive, cardiovascular, neurological and psychological health problems are significantly sleepier than people who do not have these problems.

The analysis did not show a significant difference in the EDS between workers with fixed-schedule shift work and those with shift work with variable schedules. Also, there is no difference between 


\begin{tabular}{|l|c|c|c|c|}
\hline Health problems & & ESS $\leq \mathbf{1 0}$ & ESS $\geq \mathbf{1 0}$ & p \\
\hline \multirow{2}{*}{ Digestive } & Yes & $73,0 \%(102)$ & $26,1 \%(36)$ & \multirow{2}{*}{0,007} \\
\cline { 2 - 4 } & No & $85,9 \%(158)$ & $14,1 \%(26)$ & \\
\hline \multirow{2}{*}{ Cardiovascular } & Yes & $65,5 \%(36)$ & $34,5 \%(19)$ & \multirow{2}{*}{0,002} \\
\cline { 2 - 4 } & No & $83,9 \%(224)$ & $16,1 \%(43)$ & \\
\hline \multirow{2}{*}{ Neurological } & Yes & $40 \%(2)$ & $60 \%(3)$ & \multirow{2}{*}{0,02} \\
\cline { 2 - 4 } Endocrine & No & $81,4 \%(258)$ & $18,6 \%(59)$ & \\
\hline \multirow{2}{*}{ Psychic } & Yes & $66,7 \%(8)$ & $33,3 \%(4)$ & \multirow{2}{*}{0,2} \\
\cline { 2 - 4 } & No & $81,3 \%(252)$ & $18,7 \%(58)$ & \\
\hline & Yes & $70,1 \%(94)$ & $29,9 \%(40)$ & \multirow{2}{*}{0,0001} \\
\cline { 2 - 4 } & No & $88,3 \%(166)$ & $11,7 \%(22)$ & \\
\hline
\end{tabular}

Table 5: Distribution of EDS prevalence based on current health problems of workers.

\begin{tabular}{|l|c|c|c|}
\hline & ESS $\leq \mathbf{1 0}$ & $\mathbf{E S S} \geq \mathbf{1 0}$ & $\mathbf{p}$ \\
\hline Fixed planning & $80,2 \%(89)$ & $19,8 \%(22)$ & 0,84 \\
\cline { 1 - 3 } Variable planning & $81,1 \%(159)$ & $18,9 \%(37)$ & \\
\cline { 1 - 3 } $\begin{array}{l}\text { Starting work before } \\
8 \text { am }\end{array}$ & $75,6 \%(68)$ & $24,4 \%(22)$ & 0,12 \\
\cline { 1 - 3 } $\begin{array}{l}\text { Starting work after } \\
\text { 8 am }\end{array}$ & $83,1 \%(192)$ & $16,9 \%(39)$ & \\
\hline
\end{tabular}

Table 6: Comparing the prevalence of EDS by working hours.

workers who start work before 8 am and those who start work after 8 am.

Workers exposed to conditions that can reduce alertness, especially monotonous noise, fatigue and difficulty remaining alert are significantly sleepier (Table 7).

\begin{tabular}{|l|c|c|c|c|}
\hline \multicolumn{2}{|c|}{$\begin{array}{c}\text { Conditions that may } \\
\text { reduce alertness }\end{array}$} & ESS $\leq \mathbf{1 0}$ & ESS $\geq \mathbf{1 0}$ & p \\
\hline \multirow{2}{*}{ Repetitions of acts } & Yes & $79,4 \%(216)$ & $20,6 \%(56)$ & \multirow{2}{*}{0,15} \\
\cline { 2 - 4 } & No & $88 \%(44)$ & $12 \%(6)$ & \\
\hline \multirow{2}{*}{$\begin{array}{l}\text { Need for sustained } \\
\text { attention }\end{array}$} & Yes & $70,2(120)$ & $29,8 \%(51)$ & 0,0001 \\
\cline { 2 - 4 } & No & $92,7 \%(140)$ & $7,3 \%(11)$ & \\
\hline \multirow{2}{*}{ Fatigue at work } & Yes & $75,1 \%(184)$ & $24,9 \%(61)$ & 0,0001 \\
\cline { 2 - 4 } & No & $98,7 \%(76)$ & $1,3 \%(1)$ & \\
\hline \multirow{2}{*}{ Monotonous noise } & Yes & $69,9 \%(86)$ & $30,1 \%(37)$ & 0,0001 \\
\cline { 2 - 4 } & No & $87,4 \%(174)$ & $12,6 \%(25)$ & \\
\hline
\end{tabular}

Table 7: Analysis of EDS based on exposure to working conditions that may reduce alertness.

Regarding the impact of the EDS on job performance, workers who find their performance unsatisfactory or unacceptable are significantly sleepier than others.

The analysis shows that subjects with family life that have deteriorated or who believe that working conditions have deteriorated since the beginning of work at the center are significantly more sleepy than others (Table 9).

\begin{tabular}{|c|c|c|c|c|}
\hline \multicolumn{2}{|l|}{ Job performance } & \multirow{2}{*}{$\begin{array}{l}\mathbf{E S S} \leq \mathbf{1 0} \\
86 \%(43)\end{array}$} & \multirow{2}{*}{$\begin{array}{l}\mathbf{E S S} \geq \mathbf{1 0} \\
14 \%(7)\end{array}$} & \multirow{3}{*}{$\frac{\mathbf{p}}{0,30}$} \\
\hline \multirow{2}{*}{$\begin{array}{l}\text { Excellent, and excellent } \\
\text { creativity }\end{array}$} & Yes & & & \\
\hline & No & $79,8 \%$ (217) & $20,2 \%(55)$ & \\
\hline \multirow{2}{*}{$\begin{array}{l}\text { Higher than expected } \\
\text { and average creativity }\end{array}$} & Yes & $88,8 \%(71)$ & $11,2 \%(9)$ & \multirow{2}{*}{0,036} \\
\hline & No & $78,1 \%$ (189) & $21,9 \%(53)$ & \\
\hline \multirow{2}{*}{$\begin{array}{l}\text { Satisfactory and in line } \\
\text { with expectations, } \\
\text { minimal creativity }\end{array}$} & Yes & $85,5 \%(94)$ & $14,5 \%(16)$ & \multirow{2}{*}{0,12} \\
\hline & No & $78,3 \%(166)$ & $21,7 \%(46)$ & \\
\hline \multirow{2}{*}{$\begin{array}{l}\text { In line with expecta- } \\
\text { tions, a necessary } \\
\text { improvement, no } \\
\text { creativity }\end{array}$} & Yes & $70 \%(49)$ & $30 \%(21)$ & \multirow[b]{2}{*}{0,10} \\
\hline & No & $83,7 \%(211)$ & $16,3 \%(41)$ & \\
\hline \multirow{2}{*}{$\begin{array}{l}\text { Unsatisfactory or } \\
\text { unacceptable }\end{array}$} & Yes & $43,8 \%(7)$ & $56,2 \%(9)$ & \multirow{2}{*}{0,0001} \\
\hline & No & $88,7 \%$ (253) & $17,3 \%(53)$ & \\
\hline
\end{tabular}

Table 8: Analysis of EDS based on workers' job performance.

\begin{tabular}{|c|c|c|c|c|}
\hline \multicolumn{2}{|c|}{} & ESS $\leq \mathbf{1 0}$ & $\mathbf{E S S} \geq \mathbf{1 0}$ & p \\
\hline \multirow{2}{*}{ Degraded family life } & Yes & $68,7 \%(68)$ & $31,3 \%(31)$ & 0,0001 \\
\cline { 2 - 4 } & No & $86,1 \%(192)$ & $13,9 \%(31)$ & \\
\hline $\begin{array}{c}\text { Degraded working } \\
\text { conditions }\end{array}$ & Yes & $70,6 \%(36)$ & $29,4 \%(15)$ & 0,045 \\
\cline { 2 - 4 } & No & $82,7 \%(224)$ & $17,3 \%(47)$ & \\
\hline
\end{tabular}

Table 9: Analysis of EDS as family and working conditions change.

It is noted that there is no significant relationship between EDS and sleep duration and there does not appear to be a relationship between EDS and sleep latency (Table 10).

\begin{tabular}{|l|c|c|c|c|}
\hline \multicolumn{2}{|c|}{} & ESS $\leq \mathbf{1 0}$ & ESS $\geq \mathbf{1 0}$ & p \\
\hline \multirow{3}{*}{ Sleep duration } & $\leq 6 \mathrm{~h}$ & $76,8 \%(86)$ & $23,2 \%(26)$ & \multirow{2}{*}{0,18} \\
\cline { 2 - 4 } & $>6 \mathrm{~h}$ & $82,9 \%(174)$ & $17,1 \%(36)$ & \\
\hline \multirow{2}{*}{ Sleeping latency } & $<30 \mathrm{~min}$ & $82,9 \%(145)$ & $17,1 \%(30)$ & 0 \\
\cline { 2 - 4 } & $\geq 30 \mathrm{~min}$ & $77,1 \%(108)$ & $22,9 \%(32)$ & \\
\hline
\end{tabular}

Table 10: Analysis of EDS based on sleep duration and sleep latency.

EDS is significantly higher in snorers and workers with breathing breaks during sleep (Table 11).

\begin{tabular}{|c|c|c|c|c|}
\hline \multicolumn{2}{|c|}{} & ESS $\leq \mathbf{1 0}$ & ESS $\geq \mathbf{1 0}$ & p \\
\hline \multirow{2}{*}{ Snoring } & Yes & $60,6 \%(20)$ & $39,4 \%(13)$ & 0,002 \\
\cline { 2 - 4 } & No & $83 \%(240)$ & $17 \%(49)$ & \\
\hline $\begin{array}{c}\text { Respiratory } \\
\text { breaks }\end{array}$ & Yes & $57,9 \%(11)$ & $42,1 \%(8)$ & 0,009 \\
\cline { 2 - 4 } & No & $82,2 \%(249)$ & $17,8 \%(54)$ & \\
\hline
\end{tabular}

Table 11: Analysis of EDS based on snoring and breathing pauses during sleep.

Table 12 analyzes EDS based on data from the Pichot, HAD and Berlin scales. Excessive fatigue (pichot $\geq 22$ ), depression (HAD > 13) and the likelihood of having OSA (Berlin with 2 positive categories) are significantly related to EDS. 


\begin{tabular}{|c|c|c|c|c|}
\hline \multicolumn{2}{|c|}{ Scales } & ESS $\leq 10$ & ESS $\geq 10$ & p \\
\hline \multirow{3}{*}{ Pichot } & $<22$ & $82,1 \%(243)$ & $17,9 \%(53)$ & \multirow{2}{*}{0,03} \\
\cline { 2 - 4 } & $\geq 22$ & $65,4 \%(17)$ & $34,6 \%(9)$ & \\
\hline \multirow{3}{*}{ HAD } & $<8$ & $91,9 \%(114)$ & $8,1 \%(10)$ & \multirow{2}{*}{0,0001} \\
\cline { 2 - 4 } & $8-13$ & $78,6 \%(88)$ & $21,4 \%(24)$ & \\
\cline { 2 - 4 } & $>13$ & $67,4 \%(58)$ & $32,6 \%(28)$ & \\
\hline \multirow{3}{*}{ Berlin } & Positive & $57,1 \%(8)$ & $42,9 \%(6)$ & \multirow{2}{*}{0,02} \\
\cline { 2 - 4 } & Negative & $81,8 \%(251)$ & $18,2 \%(56)$ & \\
\hline
\end{tabular}

Table 12: Analysis of the EDS based on data

from the Pichot, HAD and Berlin scales.

Multivariate analysis (Table 13)

The bivariate analysis shows that the possible determinants of EDS defined by an ESS > 10 are: Age, BMI, health problems, working conditions, starting work before $8 \mathrm{am}$, job performance ddeterioration of family life and working conditions, sleep duration, sleep latency, snoring, sleep breathing breaks, and positive scales of Pichot, HAD and Berlin.

By adjusting for the confounding factors, the multivariate analysis shows that the risk of EDS is present in workers who need for sustained attention ( $\mathrm{OR}=3.63)$, among those presenting fatigue at work ( $\mathrm{OR}=8.15)$, those who are exposed to monotonous noise $(\mathrm{OR}=2.20)$, those who snore $(\mathrm{OR}=2.87)$, and those having depression with a HAD score $>13(\mathrm{OR}=1.65)$. The risk of sleepiness is reduced in those who start work after 8 a.m. $(\mathrm{OR}=0.74)$, those with job performance higher than expected with average creativity (OR $=0.30$ ) and those with satisfactory performance and in line with expectations and minimal creativity $(\mathrm{OR}=0.37$ ).

\begin{tabular}{|l|c|c|c|c|}
\hline & \multirow{2}{*}{$\begin{array}{c}\text { Odd } \\
\text { ratio }\end{array}$} & \multicolumn{2}{|c|}{$\begin{array}{c}\text { Intervalle } \\
\text { de confiance }\end{array}$} & \multirow{2}{*}{ p } \\
\cline { 3 - 4 } & & Inf. & Sup. & \\
\hline Start time at work $\geq 8$ a.m. & 0,75 & 0,56 & 1.00 & \multirow{2}{*}{044} \\
\hline Need for sustained attention & 3,63 & 1,59 & 8,27 &, 002 \\
\hline Fatigue at work & 8,15 & 1,02 & 65,05 &, 048 \\
\hline Monotonous noise & 2,20 & 1,14 & 4,27 &, 019 \\
\hline $\begin{array}{l}\text { Job performance higher than } \\
\text { expected and average creativity }\end{array}$ & 0,30 & 0,12 & 0,73 &, 008 \\
\hline $\begin{array}{l}\text { Job performance satisfactory } \\
\text { and in line with expectations, } \\
\text { minimal creativity }\end{array}$ & 0,37 & 0,18 & 0,77 &, 007 \\
\hline Ronflement & & & & \\
\hline Depression (HAD scale > 13) & 1,65 & 1,07 & 2,54 &, 022 \\
\hline
\end{tabular}

Table 13: Multivariate analysis of the determinants of excessive daytime sleepiness.

\section{Discussion}

In order to assess the prevalence of EDS among workers at the Fez call center and its determinants, we carried out this crosssectional study using a comprehensive, self-administered, and anonymous questionnaire among workers. The sample is statistically representative of all workers at the center. Participation in this study can be considered satisfactory with a response rate of $71.5 \%$.
EDS is evaluated in the survey based on the ESS scale established by M.W. Johns of Epworth Hospital in Melbourne in 1990. This scale selected the diagnosis of EDS at a score of 10 or more after reproductible and consistent questionnaire results with the measurement of multiple sleep latency tests latency [5].

In addition, it has the advantage of being fast, easy to fill and inexpensive. This questionnaire was translated into Arabic Moroccan dialect validated by our sleep center according to the rules of transcultural translation. This version was used in our investigation.

According to definition based on ESS, the prevalence of excessive daytime sleepiness in our study is $19.3 \%$. Similar prevalence was found in two large studies that used multiple sleep latency test (MSLT) and ESS to explore EDS. From a large Southeastern Michigan random sample $(n=1648)$ representative of the U.S. population, in a subsample $(n=259)$, the prevalence of excessive sleepiness, defined as a MSLT average sleep latency of less than 6 minutes, was $13 \%$ [12]. In another sample of 6947 Wisconsin state employees, a subsample $(n=632)$, twenty-five percent had an average sleep latency of less than 5 minutes [13]. For results of ESS, in the Michigan study 20\% had ESS scores higher than 10 and in the Wisconsin study $25 \%$ had scores higher than 11. In Australian study, the prevalence of excessive daytime sleepiness among Australian workers prevalence of EDS was 16.0\% [14]. The prevalence of pathological sleepiness was $14.4 \%$ in survey among 112 emergency medical staff [15]. In France, the prevalence was very high (26\%) among 2,700 Franco-German employees [16].

We analyzed the determinants of EDS by including other issues related to sleep hygiene, lifestyle, working conditions, and different scales.

$36 \%$ of workers are overweight with a BMI between 25 and 30 but only $4.6 \%$ have a BMI above 30 . There is not a significant relationship between BMI and excessive daytime sleepiness.

In our survey, there is no difference in the prevalence of EDS between women and men. In a study representative of the Finnish population, $11 \%$ of women and $7 \%$ of men reported daytime sleepiness almost every day [17].

Some epidemiological studies have reported an association with psychiatric disorders [18-21] and physical illnesses [20-22]. In our study, workers have various gastrointestinal, cardiovascular, neurological and psychological health disorders. Bivariate analysis shows a higher prevalence of EDS among workers reporting these health problems, but these factors does not emerge as a determinant of EDS in the multivariate analysis.

Psychologically, the analysis shows that subjects with depression assessed by a score of HAD (32.6\%) are significantly more sleepy than non-depressants. Multivariate analysis shows that 
depression is closely related to EDS with an odd ratio of 1.6. One question remains: Is depression a cause or consequence of the EDS?

Sleepiness is known to affect mood with an increase in sleepiness correlated with worsened mood. In the study of Dinges., et al. when sleep was restricted in healthy males from an average of 7.4 hours to 5 hours, sleepiness was noted along with increased complaints of anxiety, mood disturbances, and fatigue [23]. On the other hand, in this study, the prevalence of severe ESD was higher in individuals with a major depressive disorder, a bipolar disorder, an anxiety disorder, or alcohol dependence. The prevalence of moderate ESD was higher in individuals with a major depressive disorder or an anxiety disorder [24].

The time of start of work before 8 a.m. is a determining factor in the EDS. In a Swedish study of train drivers the prevalence of severe sleepiness was especially high for the very early morning shift [25]. A study that explored sleep disorders and alertness among German and French employees (2001 - 2003) shows different hourly rhythms with later shift times ( 6 hours) in Germans [16]. According to the investigators, most French shift workers take their morning shifts at 4 a.m. French employees surveyed complained more about their than the German employees. In fact, workers who start their work very early are more exposed to a reduction in their night sleep duration. Which exposes them more to the SDE.

Regarding working conditions, call center workers exposed to conditions that can reduce alertness, especially monotonous noise, fatigue at work and need for sustained attention are significantly sleepier. The multi-variance analysis individualized these 3 factors as determinants of the SDE with an OR of 2.2 for monotonous noise, 8,15 for fatigue at work and 3.63 for need for sustained attention.

Multivariate analysis also shows the adverse impact of EDS on work performance. There is a strong link between the two good levels of performance and the negative risk of having an EDS: higher than expected performance $(\mathrm{OR}=0.3)$ and satisfactory performance $(\mathrm{OR}=0.37)$.

In the study of Mulgrew., et al. there were strong associations between subjective sleepiness assessed by the ESS and three of the four scales of work limitation. That is, patients with an ESS of $\leqslant 5$ had much less work limitation compared to those with an ESS $\geqslant 18$ in terms of time management $(19.7 \%$ vs. $38.6 \%, p<0.001)$, mental-interpersonal relationships (15.5\% vs. $36.0 \%, \mathrm{p}<0.001)$ and work output (16.8\% vs. $36.0 \%$; p $<0.001)$ [26]. Similarly, Grunstein and colleagues documented an increased odds ratio for work disturbance in patients complaining of frequent sleepiness in a study of obese Swedish subjects [27].

We also analyzed the evolution of family life and working conditions since the recruitment of workers. Subjects with family life that have deteriorated or who think that the working conditions have deteriorated since the beginning of work at the center are significantly sleepier than the others, but this link is not significant in the multivariate analysis.

ESD can be an essential or an associated symptom of obstructive or central sleep apnea syndrome. In our study, EDS is significantly higher in snorers and workers with breathing breaks during sleep. Multivariate analysis shows that only snoring is a determining factor in EDS with an odd ratio of 2.9. Workers with a high probability of OSA assessed by the Berlin score have a high prevalence of EDS (42.9\%), but this score do not appear as a determining factor in the multivariate analysis. This would be explained by the young age of our population and the small proportion of obese people thus reducing the risk of OSA.

Our study gives prevalence of other sleep disorders in the last 3 months such as insomnia (22.3\%), poor sleep (27.5\%), restless leg syndrome (3.7\%), sleepwalking (3.1\%), sleeping pills (15.5\%), bruxism $(13.7 \%)$ and finally probable cataplexy $(2 \%)$.

\section{Conclusions}

EDS remains underestimated among workers and particularly in shift work. Our study shows the high prevalence of EDS among these workers. Working conditions would play a decisive role in its installation. Our study also shows the individual health and social consequences and the collective consequences, and in particular the impact on performance and productivity at work. EDS should be systematically evaluated among workers to adapt working conditions and prevent its individual and collective adverse consequences.

Other studies on sleep disorders in other occupational categories have been conducted and are being analyzed in our Sleep Medicine Center.

\section{Acknowledgements}

We sincerely thank Doctors Khalil Ikram and Awatif El Moussaoui for participating to logistic of the study.

\section{Conflict of Interest}

We declare no conflict of interest and financial assistance has not been received for this study.

\section{Bibliography}

1. Rockwood K., et al. "Sleep disturbances and mortality: results from the Canadian study of health and aging". Journal of the American Geriatrics Society 49.5 (2001): 639-641.

2. Asplund R. "Daytime sleepiness and napping amongst the elderly in relation to somatic health and medical treatment". Journal of Internal Medicine 239.3 (1996): 261-267.

3. Ohayon MM., et al. "Consequences of shift working on sleep duration, sleepiness, and sleep attacks". Chronobiology International 27.3 (2010): 575-589. 
4. Philip P., et al. "La somnolence diurne excessive: diagnostic et prise en charge". Annales Medico-Psychologiques 163.2 (2005): 188-195.

5. Johns MW. "A new method for measuring daytime sleepiness: the Epworth sleepiness scale". Sleep 14.6 (1991): 540-545.

6. http://www.co-prev.be/file?fle=181

7. Guilbert P., et al. "Baromètre santé 2000. Volume 2: résultats". Vanves: CFES (2001).

8. Beck F., et al. "Baromètre santé 2005, attitudes et comportements de santé”. Saint-Denis: INPES (2007).

9. Zigmond A., et al. "The hospital anxiety and depression scale". Acta Psychiatrica Scandinavica 67.6 (1983): 361-370.

10. Pichot P., et al. "Brief Self-Evaluation Questionnaire for depressive, asthenic and anxious dimensions". Annales Médicopsychologiques 142.6 (1984): 862-865.

11. Netzer NC., et al. "Using the Berlin Questionnaire to identify patients at risk for the sleep apnea syndrome". Annals of Internal Medicine 131.7 (1999): 485-491.

12. Drake CL., et al. "Epidemiology and morbidity of excessive daytime sleepiness". Sleep 25 (2002): 91.

13. Punjabi NM., et al. "Predictors of objective sleep tendency in the general population". Sleep 26.6 (2003): 678-683.

14. WL Ng., et al. "The prevalence and characteristics associated with excessive daytime sleepiness among Australian workers". Obesity Research and Clinical Practice 7.9 (2013): 17.

15. Cankaya S., et al. "The evaluation of the effects of daytime sleepiness, anxiety and depression on the quality of life". European Psychiatry 33 (2016): 174.

16. Adam A., et al. "Effets des horaires de travail posté et de nuit sur la qualité du sommeil, la vigilance et la qualité de vie: Étude interrégionale franco-allemande". Archives des Maladies Professionnelles et de l'environnement 68.5 (2007): 482-493.

17. Hublin C., et al. "Daytime sleepiness in an adult Finnish population”. Journal of Internal Medicine 239.5 (1996): 417-423.

18. Ford DE., et al. "Epidemiologic study of sleep disturbances and psychiatric disorders. an opportunity for prevention?" Journal of the American Medical Association 262.11 (1989): 1479-1484.

19. Breslau N., et al. "Sleep disturbance and psychiatric disorders: a longitudinal epidemiological study of young adults". Biological Psychiatry 39.6 (1996): 411-418.

20. Hublin C., et al. "Daytime sleepiness in an adult Finnish population”. Journal of Internal Medicine 239.5 (1996): 417-423.
21. Ohayon MM., et al. "How sleep and mental disorders are related to complaints of daytime sleepiness". Archives of Internal Medicine 157.22 (1997): 2645-2652.

22. Nugent AM., et al. "Sleep complaints and risk factors for excessive daytime sleepiness in adult males in Northern Ireland". Journal of Sleep Research 10.1 (2001): 69-74.

23. Dinges DF., et al. "Cumulative sleepiness, mood disturbance, and psychomotor vigilance performance decrements during a week of sleep restricted to 4-5 hours per night". Sleep 20.4 (1997): 267-277.

24. Ohayon MM., et al. "Determining the level of sleepiness in the American population and its correlates". Journal of Psychiatric Research 46.4 (2012): 422-427.

25. Bayon V., et al. "Sommeil, somnolence et travail". Médecine de Sommeil 5.18 (2008): 10-14.

26. Mulgrew AT., et al. "The impact of obstructive sleep apnea and daytime sleepiness on work limitation". Sleep Medicine 9.1 (2007): 42-53.

27. Grunstein RR., et al. "Impact of self-reported sleep-breathing disturbances on psychosocial performance in the Swedish Obese Subjects (SOS) Study". Sleep 18.8 (1995): 635-643.

\section{Assets from publication with us}

- Prompt Acknowledgement after receiving the article

- Thorough Double blinded peer review

- Rapid Publication

- Issue of Publication Certificate

- High visibility of your Published work

Website: https://www.actascientific.com/

Submit Article: https://www.actascientific.com/submission.php Email us: editor@actascientific.com

Contact us: +919182824667 